\title{
ADVANTAGES AND DISADVANTAGES OF RAMAN SPECTROSCOPY IN TESTING PAPER BANKNOTES
}

\author{
Gordana JAUKOVIĆ
}

\begin{abstract}
This paper presents advantages and disadvantages of Raman spectroscopy when used for testing banknotes, i.e. in case study l, 1 and 5 dinars banknotes from a private collection dating from 1876 of numismatic value were analyzed, and in case study II, 1000 dinars banknote from circulation together with its counterfeit. In both cases banknotes were analyzed by using Raman spectrometer DXR Raman microscope at the Faculty of Physical Chemistry, with a laser of wave-length $780 \mathrm{~nm}$ at $12 \mathrm{~mW}$ of power. Specters were recorded under microscope using 50X lens in a range 1800-60 $\mathrm{cm}^{-1}$. Analyses from case study I on both specimens showed spectrum characteristic for fluorescence appearance, therefore intensive signal of fluorescence covered Raman signal. In case study II, it was established that Raman spectroscopy can reliably detect a counterfeit banknote. Research, comparisons and analyses regarding original and counterfeit 1000 dinars note were performed on red banknote surfaces.
\end{abstract}

Keywords: banknotes counterfeiting; forensics; numismatics; printing inks; protective elements; Raman spectroscopy; spectrum

\section{INTRODUCTION}

The need for multidisciplinary examination of objects with cultural-historic value emerged in order to preserve and protect them from counterfeiting. In this paper, we are focused on historical banknotes and banknotes form circulation, as an issue of importance for numismatic museums, private collectors and researchers responsible for the care of numismatic collections. The scientific detection of forgeries is an important task for numismatic researchers around the world since they are responsible for determining the authenticity as well as the historical and monetary value of their collections. Complexity of this issue is further increased by influence of time that increases transformation and degradation of pigments and binders. Banknotes and postage stamps have complex composition; thus, several methods should be used for their identification $[1,2]$. One of the approaches used in identification of materials is physicalchemical analysis, such as Raman spectroscopy. Raman spectroscopy can give qualitative, quantitative and structural information on different materials [3]. Numerous studies have been devoted to evaluating the efficiency of several analytical techniques for the detection of forgeries of banknotes form circulation [3-5]. Gaining insight into microchemical and microphysical nature of banknotes is invaluable for clarifying issues regarding the source of materials, production techniques, exchange and trade, and many other social cultural elements. Since multidisciplinary approach in examining banknotes is at its beginnings, the results of this and other similar research could contribute in finding the best solution for framework of the future comprehensive database of cultural heritage (library of pigments and materials used in the production of banknotes) [1-5].

\section{EXPERIMENTAL PART \\ 2.1 Materials and Methods}

This paper is focused on examination of pigments used in banknotes to obtain characteristic Raman spectra that serve for the authenticity assessment. For the first time in the Republic of Serbia, in 2015, the Raman spectroscopy was used to evaluate the applicability of this method for the analysis of banknotes. The results of the study were applied in two case studies; first case study was conducted on two specimens of historical banknotes from 1876, and the other examination was done in the second case study on a banknote from circulation and its counterfeit. Measurements were performed at Laboratory for micro-Raman spectroscopy at the Faculty for Physical Chemistry in Belgrade. Banknotes were examined by Raman spectrometer DXR Raman microscope (Thermo Scientific) with a laser of wave-length $780 \mathrm{~nm}$ at $12 \mathrm{~mW}$ of power. Spectra were recorded under microscope using 50× lenses in a range $1800-60 \mathrm{~cm}^{-1}$. During recording, a $10 \mathrm{~s}$ exposition with 10 repetitions was used.

\subsection{Case Study I - 1 Dinar and 5 Dinars Banknotes of Year 1876 - Money of Central Treasury: A Historical Money Description}

According to archive documents, specimens of banknotes from 1876 were printed in State Printing Works in Belgrade, but the paper was bought from supplier Le Franc and imported from Paris. Archive documents indicate that expected results should refer to spectra of "Berlin" blue, known in materials technology literature under the official name "Prussian blue" or "Paris blue" [6]. Paper surface was covered with yellowish net - impregnation $[6,7]$. Dinar banknotes from the end of the $19^{\text {th }}$ century had watermark containing figures and words denoting value, which is visible in Fig. 1a) and 1b). Law articles regarding punishments for counterfeiters were printed in textual form. 


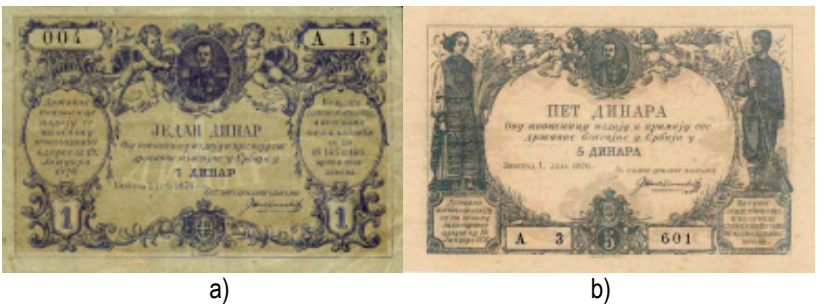

Figure 1 Watermark as a protective element in denominations of: a) 1 dinar and b) 5 dinars from 1876. Central part has figures "1" and "5", with word "DINAR" printed in Cyrillic capital letters.

\subsubsection{Evaluation of Banknotes by Raman Spectroscopy - Denominations of 1 and 5 Dinars from 1876}

Banknotes in denominations of 1 and 5 dinars from 1876 Fig. 1a) and 1b) were evaluated by Raman spectrometer DXR Raman microscope (Thermo Scientific) with a laser of wavelength $780 \mathrm{~nm}$ at $12 \mathrm{~mW}$ of power. Spectra were recorded under microscope using $50 \times$ lens in the range $1800-60 \mathrm{~cm}^{-1}$. During recording, a $10 \mathrm{~s}$ exposition with 10 repetitions was used. Spectra were corrected regarding fluorescence through use of fifth degree polynomial in a software package. In case of banknote specimens from 1876 it was impossible to identify certain pigments used in banknote manufacturing due to pronounced fluorescence. The spectrum characteristic for appearance of fluorescence was noticeable in both specimens, regardless of recorded point (both in clear paper and pigment itself) and variations of experiment conditions. The fluorescence originates (Fig. 2) from paper used for banknote manufacturing, and it was visible due to laser radiation from visible part of electromagnetic spectrum. That makes the intensive signal of fluorescence cover Raman signal, disabling pigment analysis with DXR Raman microscope. Therefore, to get reliable information, it would be necessary to implement different methods such as FTIR spectroscopy, since it is also a noninvasive method [4].

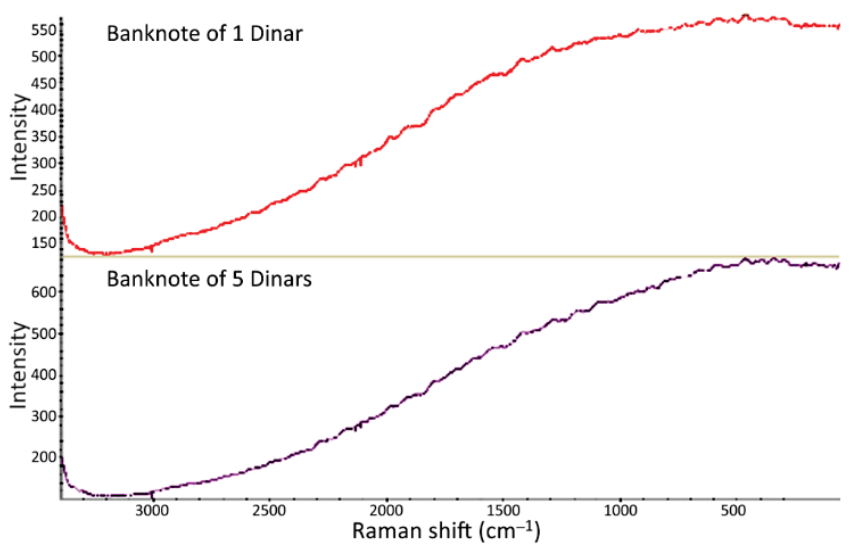

Figure 2 Pronounced fluorescence on samples of 1- and 5-dinars banknotes from 1876

\subsection{Case Study II - Circulation Banknotes, 1000 Dinars Denomination and Its Counterfeit}

Circulation banknotes, 1000 dinars denomination (Fig. 3 ) and its counterfeit, were evaluated in same conditions as in the first case study by Raman spectrometer DXR Raman microscope (Thermo Scientific) with a laser of wave-length $780 \mathrm{~nm}$ at $12 \mathrm{~mW}$ of power. Spectra were recorded under microscope using $50 \times$ lens in the range $1800-60 \mathrm{~cm}^{-1}$. During recording a 10s exposition with 10 repetitions was used. Spectra were corrected regarding fluorescence through the use of fifth degree polynomial in a software package.

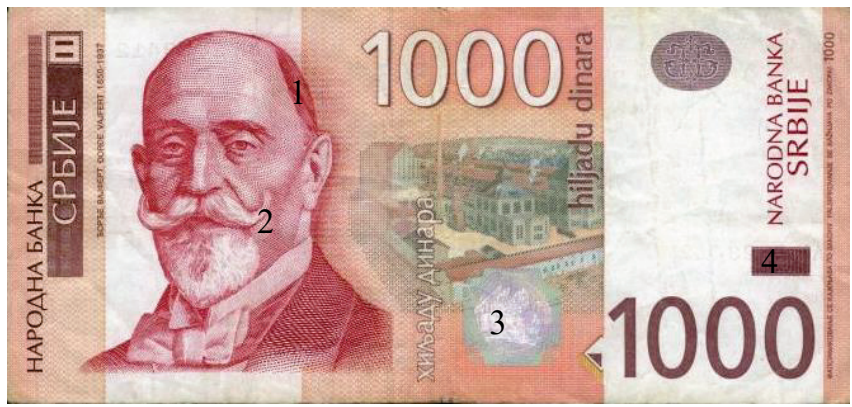

Figure 3 Marked regions of 1000 dinar banknote where Raman spectra were recorded
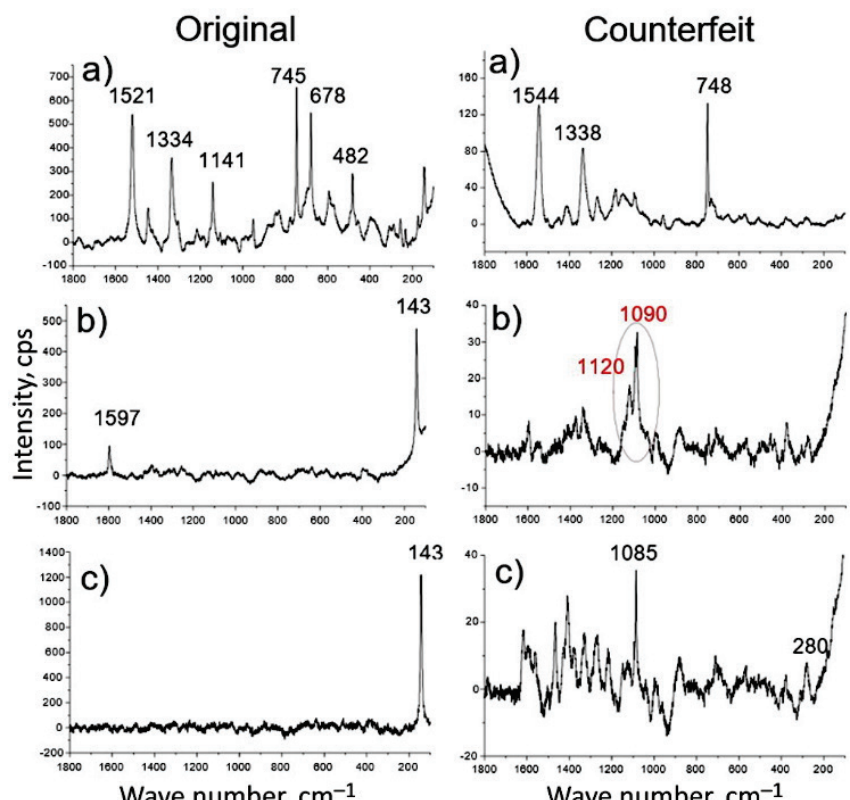

Wave number, $\mathrm{cm}^{-1}$

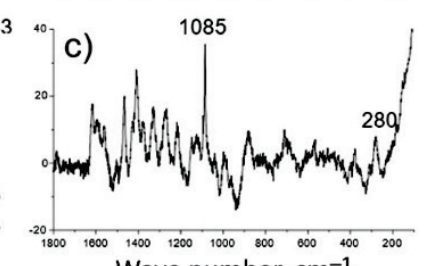

Figure 4 Raman spectra from region 1 on original and counterfeit banknote

Spectra from region 1 recorded in original and counterfeit banknote are presented in Fig. 4. Spectrum a) in original banknote based on stripes 1521, 1334, 1141, 745, 678 and $482 \mathrm{~cm}^{-1}$ can be attributed to spectrum of blue phthalocyanic pigment, since during recording with $780 \mathrm{~nm}$ laser it shows resonant effect. Resonant amplification of intensity of that pigment can cause masking stripes of other, possibly present pigments [8]. Spectra b) and c) in original banknote show intensive stripe at $143 \mathrm{~cm}^{-1}$ originating from $\mathrm{TiO}_{2}$ in anatase form. Besides that, noticeable stripe in spectrum b) is stripe at $1597 \mathrm{~cm}^{-1}$ that could arise from vibrations of aromatic rings of orange diazo pigments of pyrazoline $[9,10]$. In the same region of counterfeit banknote the spectrum received was of green phthalocyanic pigment, spectrum a), with most intensive stripes at 1544, 1338 and $748 \mathrm{~cm}^{-1}$ [11]. Unlike original banknote, counterfeit produced stripes of cellulose, i.e. of paper, spectrum b). In 
spectrum c) of counterfeit banknote most intensive stripe noticeable is at $1085 \mathrm{~cm}^{-1}$ arising from white pigment - chalk [11].

During recording of spectrum in region 2 of original banknote (Fig. 5) intensive fluorescence occurred, so just a single spectrum was recorded (after correction) with noticeable weak stripes at 1586,1560 and $1364 \mathrm{~cm}^{-1}$ of red pigment (alizarin) [8]. In the same region of counterfeit banknote green phthalocyanic pigment, spectrum a), was identified as well as chalk, spectrum b).

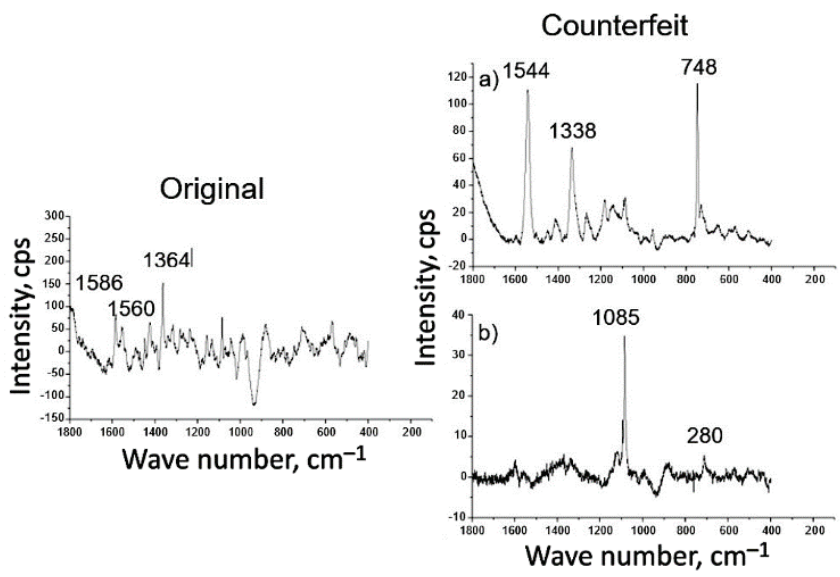

Figure 5 Raman spectra of region 2 in original and counterfeit banknote
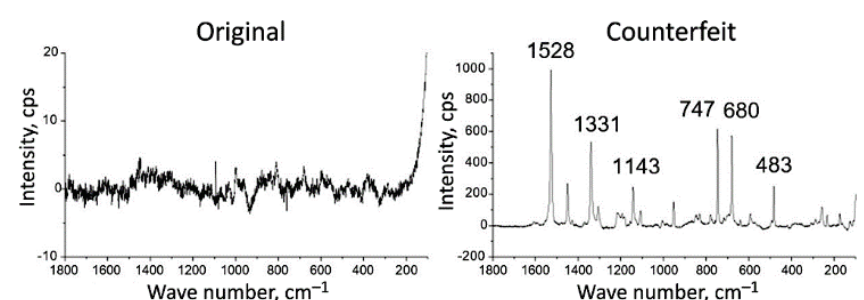

Figure 6 Raman spectra of region 3 in original and counterfeit banknote
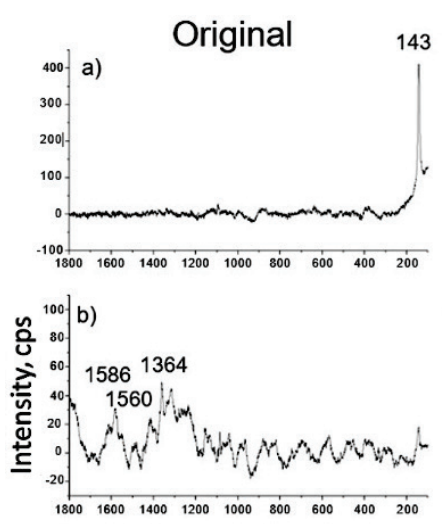

250. (c)

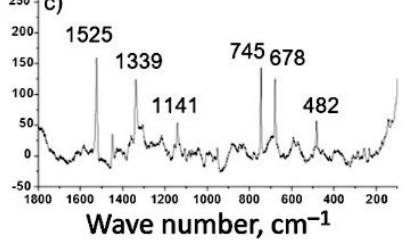

Figure 7 Raman spectra of region 4 in original and counterfeit banknote
In region 3 of original banknote (Fig. 6) spectrum that would enable identification of pigments was not received, while counterfeit banknote produced very good spectrum of blue phthalocyanic pigment.

In region 4 of original banknote (Fig. 7) $\mathrm{TiO} 2$ was identified in anatase form, spectrum a), naphthol red pigment (alizarin), spectrum b), while spectrum c) corresponds to blue phthalocyanic pigment. From counterfeit banknote received was spectrum of green phthalocyanic pigment, with pronounced stripes of cellulose at 1120 and $1090 \mathrm{~cm}^{-1}$.

\section{CONCLUSION}

The results of the measurements are given in Figs. 2, 4, 5,6 and 7. Our measurements successfully confirmed that there are advantages and disadvantages in examining banknotes with the Raman spectroscopy. Within the first case study, the analyzed specimens of historical banknotes gave unsuccessful measurements due to the spectrum characteristics. In addition, appearance of fluorescence was noticeable in both samples due to the yellowish impregnation. Recommendation for further analysis is employment of other noninvasive techniques such as FTIR. In the examination of specimens in the second case study we concluded that the Raman spectroscopy is a successful and easily obtained method applicable in forensic evaluation of circulating banknotes and counterfeits.

\section{Acknowledgement}

Many thanks to Dr Danica Bajuk-Bogdanović, research associate at the Faculty of Physical Chemistry, for assistance in recording and interpreting Raman spectra. This research was conducted in 2015 within the curriculum of $\mathrm{PhD}$ studies History and Philosophy of Science and Technology at the University of Belgrade.

\section{REFERENCES}

[1] del Hoyo-Melendez, J. M., Gondko, K., Mendys, A., Krol, M., Klisinska-Kopacz, A., Sobczyka, J., \& Jaworucka-Drath, A. (2016). A multi-technique approach for detecting and evaluating material inconsistencies in historical banknotes. Forensic Science International, 266, 329-337. https://doi.org/10.1016/j.forsciint.2016.06.018

[2] Badovinac, I. J., Orlic, N., Lofrumento, C., Dobrinic, J., \& Orlic, M. (2010). Spectral analysis of postage stamps and banknotes from the region of Rijeka in Croatia. Nuc. Instrum. Meth. A, 619, 487-490. https://doi.org/10.1016/j.nima.2009.10.174

[3] Skenderović-Božičević, M., Gajović, A., \& Zjakić, I. (2012). Identifying a common origin of toner printed counterfeit banknotes by micro-Raman spectroscopy. Forensic Science International, 223, 314-320. https://doi.org/10.1016/j.forsciint.2012.10.007

[4] Itrić, C. \& Modrić, D. (2017). Banknote characterization using the FTIR spectroscopy. Tehnički glasnik, 11(3), 83-88.

[5] Bruna, A., Farinella, G. M., Guarnera, G. C., \& Battiato, S. (2013). Forgery detection and value identification of euro banknotes. Sensors, 13(2), 2515-2529. https://doi.org/10.3390/s130202515 
[6] Hadži-Pešić, J. (1995). Novac Srbije 1868-1918. Beograd: Narodna banka Jugoslavije, Zavod za izradu novčanica i kovanog novca; Stojanović Ž. 1996. Papirni novac Srbije i Jugoslavije 1876-1996, Beograd. (in Serbian)

[7] Poznovija, M. (1991). Tehnologija sito-štampe I, Novi Sad: Zavod za izdavanje udžbenika; Radosavljević V. 2000. Konzervacija i restauracija arhivske i bibliotičke građe i muzejskih predmeta od tekstila i kože. Beograd: Arhiv Srbije i Arhiv Vojvodine. (in Serbian)

[8] de Almeida, M. R., Correa, D. N., Rocha, W. F. C., Scafi, F. J. O., \& Poppi, R. J. (2013). Discrimination between authentic and counterfeit banknotes using Raman spectroscopy and PLSDA with uncertainty estimation. Microchemical Journal, 109, 170-177. https://doi.org/10.1016/j.microc.2012.03.006

[9] Nadim, C. S., Zumbuehl, S., Delavy, F., Fritsch, A., Kuehnen, R. (2009). Synthetic organic pigments of the 20th and 21st century relevant to artist's paints: Raman spectra reference collection. Spectrochimica Acta Part A, 73, 505-524. https://doi.org/10.1016/j.saa.2008.11.029

[10] Schulte, F., Brzezinka, K.-W., Lutzenberger, K., Stege, H., \& Panne, U. (2008). Raman spectroscopy of synthetic organic pigments used in $20^{\text {th }}$ century works of art. J. Raman Spectrosc. 39, 1455-1463. https://doi.org/10.1002/jrs.2021

[11] Caggiani, M. C., Cosentino, A., Mangone, A. (2016). Pigments Checker version 3.0, a handy set for conservation scientists: A free online Raman spectra database. Microchemical Journal, 129, 123-132. https://doi.org/10.1016/j.microc.2016.06.020

\section{Author's contact:}

Gordana JAUKOVIĆ, PhD student of Belgrade University, Senior Associate, National Bank of Serbia,

Communication Department, Unit for Exhibitions and Education, 12 Kralja Petra St, 11000 Beograd, Serbia

gordana.jaukovic@nbs.rs

gordana.jaukovic@gmail.com 